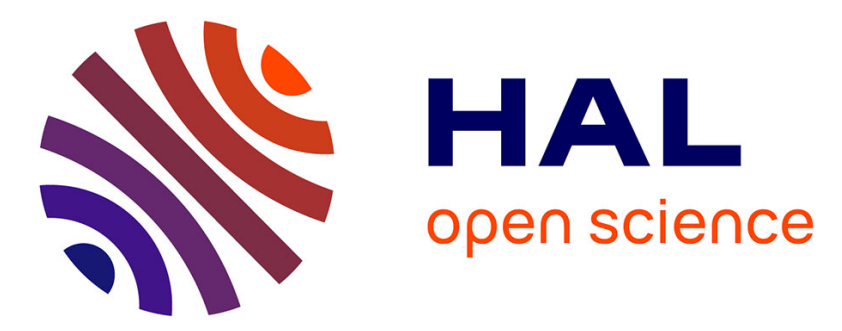

\title{
Beyond cross-functional teams: knowledge integration during organizational projects and the role of social capital
}

Caroline Sargis-Roussel, François Deltour

\section{- To cite this version:}

Caroline Sargis-Roussel, François Deltour. Beyond cross-functional teams: knowledge integration during organizational projects and the role of social capital. Knowledge Management Research and Practice, 2012, 10 (2), pp.128-140. 10.1057/kmrp.2011.45 . hal-00787480

\section{HAL Id: hal-00787480 \\ https://hal.science/hal-00787480}

Submitted on 4 May 2018

HAL is a multi-disciplinary open access archive for the deposit and dissemination of scientific research documents, whether they are published or not. The documents may come from teaching and research institutions in France or abroad, or from public or private research centers.
L'archive ouverte pluridisciplinaire HAL, est destinée au dépôt et à la diffusion de documents scientifiques de niveau recherche, publiés ou non, émanant des établissements d'enseignement et de recherche français ou étrangers, des laboratoires publics ou privés. 


\title{
Beyond cross-functional teams: Knowledge integration during organizational projects and the role of social capital
}

\author{
Caroline SARGIS ROUSSEL \\ Associate Professor at IESEG School of Management (France) \\ LEM Research centre UMR CNRS 8179 \\ c.roussel@ieseg.fr
}

François DELTOUR

Assistant Professor at Ecole des Mines, Nantes (France)

LEMNA Research centre

francois.deltour@mines-nantes.fr

\begin{abstract}
Large organizational projects must integrate the specific and dispersed knowledge of many individuals and groups to succeed. Thus, frequent exchanges between the project team and the organization's members are required. In this context, understanding of the knowledge integration process during cross-functional projects can be enhanced through the conceptual framework of social capital. A qualitative investigation of a French small and medium-size enterprise conceptualizes knowledge integration as a three-phase model: collection, interpretation, and assimilation. The case shows that the integration process is cyclical with overlaps and inter-dependencies among the phases. This study leads to refinement of the social capital role in knowledge integration and reveals the dynamics of internal and external facets of social capital. That is, internal and external social capital play differentiated roles depending on the three phases of the knowledge integration process. Finally, the study reveals the co-evolution of social capital and knowledge integration as a resulting longterm effect.
\end{abstract}

Keywords: knowledge creation; knowledge sharing; social capital; information systems; case study 


\section{Introduction}

Many companies are increasingly interested in organizational knowledge, reflecting their entry into a knowledge economy. In this area, firms need to better understand knowledge dynamics, especially in the project context (Reich et al., 2008 ; Swan et al., 2010). Cross-functional projects cover a large scope of the firm (e.g. redefinition of the information system, new product development) and are characterized by constrained timing, specific project structures, numerous and dispersed actors, specific knowledge of actors, and, finally, knowledge heterogeneity (El Louadi, 2008). Thus, crossfunctional projects constitute a rich and promising organizational context to study knowledge management because of the multi-disciplinary teams, enhancement of creative potential, and impact on project effectiveness. Project organization involves a high degree of knowledge specialization, leading to problems of coordination (i.e. how highly specialized and distributed knowledge can be effectively integrated into project activities). Consequently, efficient cross-functional projects require knowledge to be integrated as a condition of their success. Among all the knowledge management processes, knowledge integration is particularly critical in explaining performance of the firm or differences in product development performance and, more generally, in innovation (Tell, 2011). Thus, knowledge integration is a central process in knowledge management: 'Knowledge integration is a key component of knowledge application.... It premeditates the ability of organizations to (1) sense, (2) interpret, and (3) respond to new business opportunities and threats' (Alavi \& Tiwana, 2002, p. 1030). However, literature on knowledge integration remains scarce, and there is 'a lack of integrated work that provides insights into the activities conducted by organizational members in carrying out knowledge integration' (Tell, 2011, p. 19). Thus, studying knowledge integration during cross-functional projects is a challenging question we aim to address.

Knowledge integration is a common, daily activity of organizations (Grant, 1996): when two people confer, they share knowledge, which affects their previous knowledge and contributes to the creation of new knowledge, through new knowledge integration. The process of knowledge integration differs from the mechanisms of knowledge sharing or knowledge creation because it includes them in a cumulative process. Nonaka and colleagues' (Nonaka, 1994; Nonaka \& Takeuchi, 1995) view the essence of knowledge creation as the conversion of tacit knowledge into explicit knowledge. From previous contributions (Grant, 1996; Huang \& Newell, 2003; Inkpen \& Dinur, 1998; Okhuysen \& Eisenhardt, 2002; Tell, 2011), knowledge integration can be analyzed more broadly than the complementarity of tacit and explicit knowledge, reflecting more of an institutionalization process. In line with the literature, we define knowledge integration as the combining of existing knowledge 
leading to the creation of new knowledge that is organizationally shared and institutionalized. Achieving knowledge integration in organizations takes time because many actors are involved.

In this research, our objective is to understand and analyze the knowledge integration process during cross-functional projects. This objective helps fill the gap between knowledge management literature and project management literature. With an understanding of knowledge integration as a multi-level institutionalization of knowledge, we study the effective influence of social capital through a refinement of previous approaches. Because relational factors strongly influence knowledge integration (Bhandar et al., 2007 Newell et al., 2004), it is relevant to investigate the role and influence of social capital on the knowledge integration process during a cross-functional project. First of all, we define the context of our research by proposing a literature review of knowledge integration studies in project settings and outlining the knowledge integration stakes in a crossfunctional project. Then, we analyze the role of social capital in knowledge integration, adopting Nahapiet and Ghoshal's (1998) conceptual framework. In the following section, our empirical investigation details a longitudinal case study of an information system project. This case allows us to empirically identify the phases of knowledge integration and to propose an original model of the knowledge integration process. We discuss the role of social capital in the phases of knowledge integration, which leads to several insights into its effect. We then present the main conclusions, limitations, and directions for further research in this area.

\section{Conceptual background}

\section{Understanding knowledge integration during cross-functional projects}

The literature describes knowledge integration in very different ways. The first noticeable characteristic of integration is the creation of new knowledge from existing knowledge. This characteristic differentiates knowledge integration from knowledge sharing; according to Okhuysen and Eisenhardt (2002, p. 383), in knowledge sharing, 'individuals identify and communicate their uniquely held information', and in knowledge integration, 'several individuals combine their information to create new knowledge'. Knowledge sharing is a starting point for knowledge creation and knowledge integration. So, knowledge integration is a cumulative process. The second characteristic of knowledge integration is organizational institutionalization of new shared and created knowledge. Huang and Newell (2003, p. 167) define knowledge integration as 'an ongoing collective process of constructing, articulating and redefining shared beliefs through the social interaction of organizational members'. This second characteristic is not systemically developed in 
the literature, but we believe it is significant because institutionalization is evidence of the reality and effectiveness of knowledge integration. Tell (2011) reviews more than 30 definitions of the knowledge integration concept and indicates that the most widely accepted definition is that which considers knowledge integration as a combination of specialized, differentiated, but complementary knowledge. Thus, our definition of knowledge integration, in line with the leading literature on this topic, apprehends it as the combination of existing knowledge leading to the creation of organizationally shared and institutionalized new knowledge.

Knowledge integration is a fundamental underlying process in the context of project settings (Maaninen-Olsson et al., 2008) to ensure proper coordination and effective achievement of the project goals. Project settings are characterized by tensions: needs for coordination of activities, integration of knowledge and simultaneously autonomy requirements. Projects can be considered as repositories of knowledge at multiple levels and project contexts offer a variety of possibilities for exploring knowledge-related issues (Sydow et al., 2004; Organization Studies Special Issue, 2004). Project characteristics influence knowledge integration: constrained timing enables people to become involved quickly and to directly accomplish major tasks. Nevertheless, knowledge sharing may be more superficial. A cross-functional project involves a constellation of actors with specific expertise and varied knowledge. These actors accumulated specific experience which is not automatically transferred within the project or across projects structures (Swan et al., 2010). Moreover, people don't necessarily know one another before the beginning of the project. Meeting places are specific structures of the project that enable people to share and create organizational knowledge and facilitate geographical proximity. The project enables the sharing of both tacit and explicit knowledge by facilitating close relationships and interactions among actors (Fong, 2003). Because of these characteristics, a project creates a specific opportunity to integrate diversified knowledge in the organization. In cross-functional projects, the challenge of knowledge integration is to combine individual knowledge to build collective and then organizational knowledge (Huang \& Newell, 2003). This process is cyclical (Carlile \& Rebentisch, 2003) and implies frequent formal interactions between individual holders of specific knowledge and project team members (Okhuysen \& Eisenhardt, 2002). Knowledge is dispersed within the organization and is located at different levels, including individual, collective, organization, and inter-organizational (Kogut \& Zander, 1992; Nonaka, 1994). According to Inkpen and Dinur (1998, p. 456), 'The transformation occurs in a dynamic process involving various organizational levels and carriers of knowledge. Specific learning processes are at work at each level. At the individual level, the critical process is interpreting and sense making; at the group level, it is integrating; and at the organizational level, it is integrating and 
institutionalizing (Inkpen and Crossan, 1995)'. These different levels of analysis suggest the existence of several steps in the global knowledge integration process. It therefore is important to study how these different steps occur and how they connect.

Prior research has investigated the knowledge integration process in project settings. Several results regarding the integration process and the factors influencing it have been established and thereby enable us to account for the relational aspects of the process. Huang and Newell (2003) suggest that members of project teams have varied and specific knowledge and competences; thus, project teams have access to cross-functional knowledge but also must solve integration problems due to multiple perspectives. In addition, they must obtain enough support from the actors to build a collective identity to reduce political conflicts.

As mentioned previously, knowledge integration during cross-functional projects is a multi-level process. Prior research has raised the question of leading knowledge integration through different levels in a project. For example, Fong (2003) shows that boundary spanners are necessary in multidisciplinary projects to deal with dispersed knowledge and expertise and hierarchical barriers in the process. Following Fong (2003), Maaninen-Olsson et al. (2008) analyze how knowledge is integrated between different work groups and show that the question of boundaries spanning across different levels is particularly tricky. In the context of new project development, Enberg et al. (2006) highlight the importance of the individuals' experience accumulation and the complementary role of the collective for knowledge articulation. They propose an iterative model of the individual/collective dynamics based on interaction and action and depending on task characteristics to understand knowledge integration. Enberg et al. (2006) study knowledge integration in a project team comprised of a small core group of team members with an integrative role and other members with more specific tasks. Their main findings suggest that knowledge integration in a project does not need equality of participation, allowing for the notion of segregated team.

Prior research also has addressed more directly the question of the influencing factors on the knowledge integration process in a project context. In the context of the development of radical product innovation, Schmickl and Kieser (2008) argue that people engaged in product development do not necessarily need to ensure cross-learning to perform more effectively; rather, they prefer to integrate their knowledge through structural mechanisms. Tell (2011, p. 12) lists three types of factors that influence knowledge integration: task characteristics (e.g. complexity, uncertainty, 
novelty, heterogeneity), knowledge characteristics (e.g. internal vs. external, tacit vs. explicit, related vs. unrelated), and relational characteristics (e.g. social capital, level of interaction, history).

Among all the factors that influence the knowledge integration process during cross-functional projects, several (e.g. a lack of familiarity or acquaintance between people, different languages, sense making, lack of trust, physical distance) may cause organization members to fail in using critical knowledge or integrating knowledge (Becker, 2001; Huang \& Newell, 2003, Wang et al., 2006). These results lead us to consider social capital a particularly relevant conceptual framework for studying the achievement of knowledge integration.

\section{Knowledge integration and the social capital of the project team}

Management literature has recently explored social capital (Adler \& Kwon, 2002), which is defined as 'the sum of the actual and potential resources embedded within, available through, and derived from the network of relationships possessed by an individual or social unit. Social capital thus comprises both the network and the assets that may be mobilized through that network' (Nahapiet \& Ghoshal, 1998, p. 243). We consider social capital a resource that results from social relationships, which are available to individuals or to organizational units within a firm. In our study, we focus on the social capital of the project team that arises from the social capital of each team member.

Social capital remains a major concept of social sciences, employed in different disciplines and at different levels of analysis (Payne et al., 2011). In the field of organization studies, Nahapiet and Ghoshal's (1998) main contribution is providing a better understanding of social capital, defined as a multi-dimensional construct based on structural, cognitive, and relational dimensions: (1) the structural dimension refers to the connections among actors, links, networks, density, and hierarchical structure; (2) the relational dimension describes the types of relationships among people, such as trust, respect, norms for interactions, and personal obligations or expectations; and (3) the cognitive dimension refers to resources from shared representation and interpretation, a common language to facilitate interactions, and the development of common sense making. These three dimensions are used in multiple ways; for example, Kianto and Jaakowski (2010) study the influence of structural, cognitive, and relational dimensions of social capital on organizational growth. Newell et al. (2004) operationalize the concept of social capital through these three dimensions to understand knowledge management issues. 
Focusing our attention on the specific context of project realization, we examine the results of two studies mobilizing qualitative methodologies. Newell et al.'s (2004) main finding lies in the need for project team members to create strong ties with others to share common objectives and meanings. Another result is the use of the social capital of group members to access dispersed organizational knowledge to achieve the objectives of the project. Bhandar et al. (2007) insist on the differentiated roles of social capital during the phases of a project at an inter-organizational level. Social capital thus is a motivator to launch the project, an integrator of diverse knowledge during project realization, and a facilitator to achieve changes when the project affects the organization.

However, the concept of social capital presents some limitations and can have some undesirable effects on the knowledge integration process. The robustness of the social capital approach has been questioned, and the difficulties in empirically studying it have been raised (Locke, 1999). Social capital may reinforce organizational routines and inhibit knowledge creation (Leonard-Barton, 1995). Common norms in a team or a company (the relational dimension of social capital) provide a fertile context for knowledge creation but also could establish rigidities (Leonard-Barton, 1995; Maurer \& Ebers, 2006); they can also lead to the emergence of information and knowledge barriers (Edelman et al., 2004). Though taking into account these limitations, much of the literature supports the opposite perspective, and we consider the social capital approach a relevant theory to understand knowledge integration. Previous literature has begun to study the role of social capital on knowledge integration during projects. From our literature review of knowledge integration, we offer the following case study to improve understanding of the influence of social capital on knowledge integration in a cross-functional project.

\section{Research method}

Given the objectives of the research to investigate the cyclical and processional nature of knowledge integration and to analyze the influence of social factors during the process, we conducted a qualitative empirical study through a single case study. This case study aims to provide theoretical insights into both the knowledge integration process and the influence of social capital. A qualitative methodology enables an in-depth investigation of this process during a cross-functional project. We study one global information technology (IT) project in a French small and medium-sized enterprise (SME) through a longitudinal case study (Yin, 2003). We use a qualitative research method (Miles \& Huberman, 1994) based on an interpretative approach. The firm operates in the services sector; its main activities are consulting and training. The company faces an increasingly competitive 
environment in both activities. The IT project is strategic for this company and involves the integration of the information system across all company functions. At the time of the empirical study, the project was still running, which enabled us to consider the impact of time on the project and to minimize biases caused by individual member's ex post rationalization. A longitudinal case study also helps inform the history and context of the process being studied.

Data collection was mainly performed in 2006 and 2007 and consisted of interviews (nine interviews of more than one hour each), observation (before and after meetings), and gathering of internal electronic and paper documentation (documents from the intranet, such as analysis of the procedures, or hard copies of documents, either from the IT provider or meeting minutes or from project progress reports). The use of different sources of data helps validation and improves the reliability of the study (Miles \& Huberman, 1994). All the members of the project team were interviewed once, apart from the project manager who was interviewed twice. Four employees in different departments were also interviewed. The focus on the project team members was explained by the desire to study the influence of the project team's social capital on the knowledge integration process. The employees in the different departments of the company were considered the owners or depositories of the knowledge involved in the IT project. We conducted the interviews after the launch of the project over a six-month period.

Empirically appreciating social capital is delicate, and the investigation tools employed by previous research are scarce. We took the interview guide from the available literature, incorporating the insights of Nahapiet and Ghoshal (1998), Tsai and Ghoshal (1998), Maurer and Ebers (2006), and Sherif et al. (2006), and divided it into four parts. After a brief presentation of the interviewee, the first part of the guide comprised general questions about the project: its origins, evolution, and context (e.g. role of the team members, project structure, management of the project and tools). The second part identified the different types of knowledge in the project, its nature, and dynamics. Questions pertained to communication channels between functions and the type of knowledge required for the project, for example, to identify whether the knowledge from another department is understandable or relevant. The third part of the interview guide assessed the social capital of the project team by questioning the interaction intensity between the project team and departments, corporate culture, trust, reciprocity, shared language, and common previous experience of group work, among others. The last part pertained to the results of the knowledge integration process (which type of knowledge is created, shared, and finally institutionalized) and also modifications in 
the knowledge of each individual (e.g. technical vs. business knowledge). All the interviews were recorded and transcribed.

We conducted a qualitative data analysis, including content analysis, on all the materials (transcription of interviews and documentation). Data analysis used the NVIVO 7 software. We coded all the interviews using 14 codes to describe the context of the project; the nature and type of knowledge in the project; the structural, relational, and cognitive dimensions of social capital; and the knowledge integration. The coding enabled us to identify the main recurring themes, comments, and facts in line with our research issues. Data analysis helped identify the knowledge integration process and distinguish several steps. We operationally identified the three dimensions of social capital using an operationalization of Nahapiet and Ghoshal's (1998) framework. We evaluated the structural dimension of the project team's social capital by the intensity of the interactions and through the actors' centrality, which we measured by counting the occurrence of the names of the project's actors mentioned during interviews. We identified the relational dimension of social capital through the study of trust, reciprocity, and identification. Two characteristics helped define the cognitive dimension of social capital: language and shared values. We created matrices to analyse the relationships between these factors (Miles \& Huberman, 1994) and the role of the project team's social capital in the knowledge integration process.

\section{Case study: The Phenix Project}

As mentioned previously, we undertook the case study in a French SME, referred to herein as Polaris (the names of the company and the IT project are anonymous). The company's main business is in consulting and training, in the field of engineering. Facing high competition, the firm experienced several business difficulties at the beginning of the 2000s. At the end of 2005, a new board of directors was appointed and subsequently decided to change the strategic position and organization of the company. The new top management believed that transforming the information system would help ensure the match between the firm and its changing environment. As a result, the management created an information systems (IS) department and launched the Phenix Project in January 2006. At the time of the study, the company employed roughly 100 people, and most of the employees had worked at the firm for more than 15 years; however, the company was developing an ambitious plan for recruitment and renewed one-third of its positions by recruiting new and younger employees who brought fresh eyes to the company business. 
Initially, the information system was very poor, and business applications were largely independent. Several databases were spread among the different departments with little or no centralization. Polaris's organizational culture was also compartmentalized with little interaction between departments. Professional and business knowledge was dispersed throughout the organization, and the intensity of communication between people was low. According to a member of the IS department, 'Polaris is an old company; people work separately within their own specific areas. [...] We noticed that there were "privileged" departments in our company and there were a lot of difficulties in the diffusion of information. There were brakes which were very, very, very strong brakes to communication in our company. There were some departments which were totally autonomous.'

The Phenix Project was the first cross-functional project in the company involving technological and organizational dimensions. Polaris's new top management wanted to obtain quick, concrete results. When launching the project, their first decision was to adopt the Enterprise Resource Planning software. To carry out the project quickly, the project team was voluntarily limited to four members: the new CEO, the head of the new IS department, one user representative from the operational centre, and a newly hired project manager (see Table 1). All of them, except the CEO, had real operational involvement as a member of a project team. They were all relatively new to the firm, compared with the average time workers spend at Polaris overall.

\begin{tabular}{llll}
\hline Name & Age & Position & Elements of professional biography \\
\hline Luke & 37 & Project manager & $\begin{array}{l}\text { Is newly hired (January 2006) to manage the Phenix Project. Has } \\
\text { external view of the project with a general background in management } \\
\text { and organization and } 10 \text { years experience in production and } \\
\text { organization. }\end{array}$ \\
\hline Nicolas & 50 & $\begin{array}{l}\text { Operational } \\
\text { representative }\end{array}$ & $\begin{array}{l}\text { Has worked at Polaris for 2 years. Is a member of the project team as a } \\
\text { referent and a support for the administrative functions. Knows the } \\
\text { organization of Polaris in great depth. }\end{array}$ \\
\hline Robert & 40 & IS Manager & $\begin{array}{l}\text { Has worked at Polaris for 2 years. Is head of the new IS department. Is } \\
\text { a member of the project team because of his competences in } \\
\text { information systems. }\end{array}$ \\
\hline William & 45 & CEO & $\begin{array}{l}\text { Has worked at Polaris since September 2002. Appointed CEO just } \\
\text { before the launch of the project. Was formerly production director of } \\
\text { Polaris. Is a link between the project team and the board of directors. } \\
\text { Has previous experience in managing information systems projects. }\end{array}$ \\
\hline
\end{tabular}

Table 1 The Phenix Project team

The project team met every week, with the board of directors, if necessary. The aim of the project team was to begin implementing and using several software modules by September 2006. The pace of the Phenix Project was fast, relative to its ambitions and its cross-functional scope. Using the 
Enterprise Resource Planning implementation framework proposed by Nah and Lau (2001), we identify several steps in the Phenix Project (see Table 2).

\begin{tabular}{|c|c|c|c|}
\hline Steps & & Date & Description \\
\hline \multirow{2}{*}{ 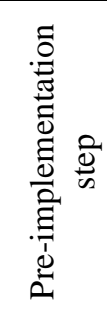 } & $\begin{array}{l}\text { Adoption } \\
\text { decision }\end{array}$ & Nov.05 & $\begin{array}{l}\text { William, new CEO, launches the project for a new information system at } \\
\text { Polaris }\end{array}$ \\
\hline & Acquisition & $\begin{array}{l}\text { Jan.06 to } \\
\text { Ap. } 06\end{array}$ & $\begin{array}{l}\text { Quick analysis of the existing information system: interviews with employees } \\
\text { in each department by Luke, the project manager, and Nicolas, the operational } \\
\text { representative } \\
\text { Definition of the mission statements, sent to a dozen software vendors by } \\
\text { Luke. Establishment of a short list of } 5 \text { providers. Selection of one software } \\
\text { provider based on price, adaptability, and experience }\end{array}$ \\
\hline \multirow{2}{*}{ 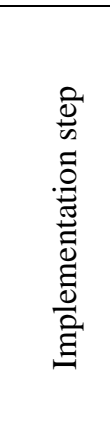 } & $\begin{array}{l}\text { Parameterization } \\
\text { and adaptation }\end{array}$ & $\begin{array}{l}\text { Ap.06 to } \\
\text { Aug. } 06\end{array}$ & $\begin{array}{l}\text { Interviews with employees in each department by Luke, the project manager, } \\
\text { and the software provider } \\
\text { Creation of the IT solution based on the existing software and the results of } \\
\text { the employees' interviews } \\
\text { Project team meetings each week (Luke, Nicolas, Robert, and William) }\end{array}$ \\
\hline & $\begin{array}{l}\text { Operational } \\
\text { implementation }\end{array}$ & $\begin{array}{l}\text { Aug.06 } \\
\text { to Dec.08 }\end{array}$ & $\begin{array}{l}\text { Implementation of the first module (customer relationship management) in } \\
\text { Sept. } 06 \\
\text { Training of the employees } \\
\text { Coexistence of both systems during several months } \\
\text { Continuous implementation of the modules managed by Luke and the } \\
\text { software provider }\end{array}$ \\
\hline
\end{tabular}

Table 2 Description of the Phenix Project

\section{Knowledge integration: a three-phase model}

From the individual, collective, and organizational levels of knowledge described in the conceptual background part, the Phenix case enables us to build a model of the knowledge integration process during cross-functional projects. Our model comprised three phases-collection, interpretation, and assimilation—supporting different levels and mechanisms of integration.

\section{Collection phase}

In the collection phase, individual owners of specific knowledge create value by integrating knowledge in groups. This phase represents the locus of transformation of individual, specialized, dispersed, and sometimes tacit knowledge into collective knowledge. To achieve this phase, individual knowledge holders working in the services or functions of the organization must be identified.

At Polaris, Luke and Nicolas interviewed heads of departments to write the terms of reference for potential providers and to evaluate employees' expectations. Some heads of departments consulted their teams before the interviews or received assistance from an employee. As one employee explained: 'Our manager knows the tools we use and the processes; so, he met with Luke. But I don't 
know if he has an in-depth knowledge of our work. It's very important to involve and integrate final users and participants to explain our work. Our manager has not performed operational tasks for three years'. A member of a support service added: 'It's important to have someone in each department who possesses the knowledge and who is able to transfer it to the members of the team project'. A second set of interviews took place, conducted by Luke with a member of the IS vendor firm. These new interviews focused on the technical and organizational dilemmas of implementation and also on each department's activities. Luke explained the purpose of this second set of interviews: 'Through these interviews, the IS vendor worked on the technical aspects and I worked on the processes. [...] It was useful and it helped me to refresh the processes we had formalized in the project team'. In summary, these interviews helped identify and collect dispersed knowledge throughout the organization-that is, the technical knowledge (about the information system and how it works) and the processional knowledge (e.g. how to deliver high-quality service to a customer). These interviews helped create collective knowledge at the project team level based on individual dispersed knowledge.

\section{Interpretation phase}

The second phase, interpretation, enables organizational knowledge to be produced from collective knowledge. During this phase, a common meaning and an organizational interpretation of the collective varied knowledge are created. The project team is the ultimate organizational integrator and plays the role of mediator of the collective knowledge. Efficient interpretation requires recognition of the individual holders of knowledge and the handling of intensive exchanges and frequent interactions between project team members.

Empirically, using the two sets of interviews conducted by Luke and Nicolas in the collection phase, the members of the project team together described and formalized the processes of the firm. Following the first phase of interviews, the work focused on three main processes: 'We have business processes and support processes. At Polaris, there are three key business processes: production, technology and research and development; they need the support processes in order to work' (William, Polaris's CEO). This phase of process formalization lasted four months and took place at the same time as the second set of interviews, which were performed in collaboration with the IT vendor. Thus, knowledge gathered was refined and the interpretation continued: 'We presented the results of the interviews; we described the processes to the project team' (Nicolas). Finally, the analysis of the main processes in the company was completed, bringing some unexpected results. For example, some processes or sub-processes seemed critical even if they were not 
identified as important at the beginning of the project. This was the case for customer relationship management. Conversely, work scheduling, which previously was a critical sub-process in the production process, was revealed to be less important. All these elements of process description and refinement refer to the creation of organizational knowledge. Interpretation of knowledge occurs while the project is in process.

\section{Assimilation phase}

The last phase of the model is assimilation. Tangible institutionalization of organizational knowledge takes place at this point. The essence of this phase is the diffusion and assimilation of organizational knowledge created in the project team from the two previous phases. The consequence is the modification of the individuals' knowledge in the organization through the spread of new organizational knowledge among company members.

Ten months after the launch of the Phenix project, the new information system was implemented into two departments at Polaris. The system reflected the institutionalization of the new knowledge created: technical and business knowledge. Technical knowledge pertains to IT skills—for example, how individuals use the new information system to schedule the training of a new customer. One example of business knowledge is the development of new databases on customers' sector of activities. To succeed in the implementation and, thus, in the institutionalization of knowledge, the project team uses communication tools, such as general meetings with all the employees, specific meetings with the employees of the departments involved, and training. Users are highly involved in these activities because 'they are the knowledge owners of how to perform a process at Polaris and it is necessary to have people who know the activity in an operational way to implement the new system' (a member of the administrative department). This time presented an opportunity for substantial feedback between the individual users of the new information systems and the IS provider, with the support of Luke, whose role was to centralize all questions and requests: 'We have built the new information system in common with the users, but, after implementing it, they sometimes changed their opinion and we had to go back to a previous version. So, we test whether the tool works, users send us their ideas and requests and, after this, we decide to change or not'. Robert, the IS manager also stated, 'There is feedback between the users and the project team to adapt the new information system'. These multiple events helped spread and assimilate the new knowledge created to the individuals in the firm. Consequently, they allowed completion of the assimilation phase. This phase lasted two years and was finished by the end of 2008; it was the longest phase in the project. 
These three phases constitute the knowledge integration model in a cross-functional project (see Figure 1). This model emphasizes that knowledge integration can be a temporally oriented, dynamic, cumulative process that implies several levels of interaction.

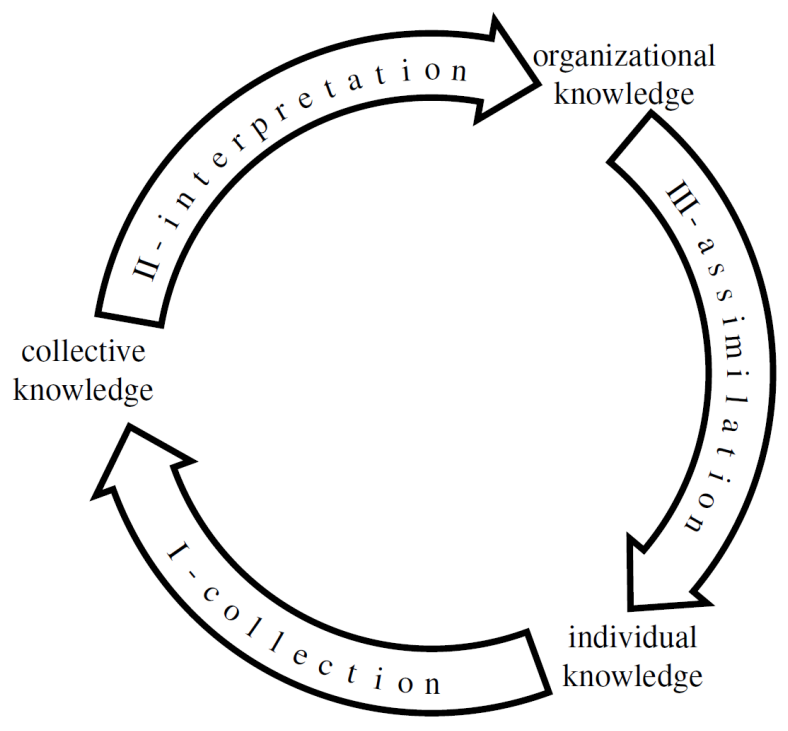

Figure 1 Knowledge integration process.

Conceptually, this model provides a clear and generic framework to understand knowledge integration during cross-functional projects or large projects involving multiple sources of knowledge. It is specifically designed for project contexts that can foster knowledge integration. Thus, it differs from the continuous improvement context of organizational learning (Spender, 2008), in which the scope is larger. Our model focuses on the project context (more knowledge intensive, timely constrained, and monitored) compared with more general models such as that of Crossan et al. (1999), which deals with the general phenomenon of organizational learning. For example, Crossan et al. use their 4I model to explain the success of a firm (Apple), not a specific project.

During a project's progress, each of the three phases of knowledge integration must be successfully completed for the entire process to take place effectively. The effective transition from one phase to another may include feedback loops or simultaneous achievement. The case of the Phenix Project offers several insights. During the project, the first two phases of integration seem to be closely intertwined and not fully sequential. For example, interviews with the heads of departments took place before and after the formalization of the work processes. The collection phase can be analyzed as directly supporting the interpretation phase. The content of the exchanges inside each department 
was organized to feed the work back to the team project level. This feedback allowed the project team to refresh the processes after they had formalized them. Thus, the case study confirms the leading role of interface integrators who connect the phases of integration. Interface integrators are members of the project team and act as boundary spanners who facilitate knowledge sharing and exchange and who assist in crossing the hierarchical and expertise barriers between people. Consequently, the integration process requires the coordination of interface integrators because of the cyclical nature of the process with overlaps between the different phases. Given the highly relational nature of the integration process and the importance of the organizational institutionalization of new shared and created knowledge, we investigate and discuss the role of the social capital in this process and develop several main results from our case study of the crossfunctional project.

\section{Social capital and the model of knowledge integration}

\section{Internal and external facets of social capital in knowledge integration}

The three dimensions of social capital - structural, relational, and cognitive - that Nahapiet and Ghoshal (1998) propose reflect the most relevant existing typology (e.g. Kianto \& Jaakowski, 2010; Newell et al., 2004). By analyzing our data, we can validate the three classical dimensions identified in our empirical study (see Table 3, in line). We refine these three dimensions by distinguishing different scopes for social capital. Namely, differentiating two facets of the social capital, one internal and one external, highlights the dynamics of knowledge integration: because the project team plays a key role in coordinating different levels of knowledge integration (Okhuysen \& Eisenhardt, 2002), the members of the team must interact with individual holders of knowledge and participate in integrating knowledge at both the group and the organizational level. The social capital of the team is mobilized with the people outside the team, but this social capital also is important for the members inside the team (see Table 3, in column).

On the one hand, the internal facet of social capital refers to all the resources available from the network of relationships exclusively within the project team. For example, the project team meetings were particularly frequent and important between April and August 2006 when the project team formalized processes at Polaris (interpretation phase). On the other hand, the external facet of social capital refers to all resources available from the network of relationships between the project team 
and all other members in the organization. External social capital of the project team was mobilized by Luke in particular when dealing with face-to-face interviews.

\begin{tabular}{|c|c|c|}
\hline $\begin{array}{l}\text { Structural } \\
\text { dimension }\end{array}$ & $\begin{array}{l}\text { Frequent interactions between team members. } \\
\text { Central position of the project manager (Luke) } \\
\text { working full time on the project, centralising all } \\
\text { communication flows } \\
\text { 'We are a small team, we work together daily' } \\
\text { (Nicolas) }\end{array}$ & $\begin{array}{l}\text { Interactions at the beginning of the project (April- } \\
\text { September 2006) and to facilitate implementation } \\
\text { 'We were informed early, at the beginning of the } \\
\text { project. Luke came several times. He asked me to } \\
\text { explain what I did and how I did it. He took notes. } \\
\text { He made the links with the IS provider. I told him } \\
\text { how it worked and he sent it to the IS company' (a } \\
\text { member of a support department) }\end{array}$ \\
\hline $\begin{array}{l}\text { Relational } \\
\text { dimension }\end{array}$ & $\begin{array}{l}\text { Existence of trust, reciprocity, and high level of } \\
\text { support between the members of the team } \\
\text { High identification with the project } \\
\text { 'We have a good team with high motivation' } \\
\text { (Robert); 'The climate is favourable to change, we } \\
\text { build our organization on success' (a member of } \\
\text { the board of directors) }\end{array}$ & $\begin{array}{l}\text { Existence of trust between the members of the } \\
\text { firm. Low level of reciprocity and support due to a } \\
\text { compartmentalized way of working } \\
\text { High identification with the project } \\
\text { 'I work alone on this task. I can't discuss my work } \\
\text { with any colleagues. Everybody works in his own } \\
\text { area. There are more or less regular contacts' (a } \\
\text { member of a support department) }\end{array}$ \\
\hline $\begin{array}{l}\text { Cognitive } \\
\text { dimension }\end{array}$ & $\begin{array}{l}\text { Shared language } \\
\text { Incomplete common background but rapid rise in } \\
\text { shared values } \\
\text { 'I don't have the same experience and I haven't } \\
\text { thought to ask these types of questions; it's } \\
\text { interesting to work together' (Nicolas) }\end{array}$ & $\begin{array}{l}\text { Common language regarding the project created } \\
\text { through several actions } \\
\text { 'The purpose of the project newsletter is to explain } \\
\text { the different phases of the project, the vocabulary, } \\
\text { the content of change' (William) } \\
\text { 'It's the first major project in the company; } \\
\text { previous projects occurred only between two } \\
\text { departments' (a member of a support service) }\end{array}$ \\
\hline
\end{tabular}

SOCIAL

CAPITAL

Internal facet

External facet

Table 3. Characteristics of social capital of the project team: From structural, relational, and cognitive dimensions to internal and external facets

In considering the key features of social capital in the Phenix Project, we found that the high intensity in the project team contrasted with the limited interactions in the organization. Luke and Nicolas ensured the links between the project team and the rest of the organization. Employees became more involved in the project when the modules began to be implemented. On the relational dimension of social capital, both internal and external facets of social capital presented a high level of identification with the Phenix Project. All firm members were convinced of the necessity for change. For the cognitive dimension of social capital of the project team, the results were not the same for the internal and the external facets. Even if a common language existed within the project team since the beginning of the project, it needed to be developed throughout the organization. The project team favored shared values by the common history of two of its members, Nicolas and Robert, but there was no real past experience in the company regarding such a global project. 


\section{Differentiated role of social capital in knowledge integration}

The empirical study of the social capital during a cross-functional project leads us to consider two complementary mechanisms of social capital - the classic view of social capital (structural, relational, and cognitive) and the internal and external facets — shedding new light on the phenomenon and reflecting the specificities of the cross-functional project context.

In the Phenix Project, the structural, relational, and cognitive dimensions influenced the whole process of knowledge integration: frequent informal interactions, the existence of shared points of view, and trust (among others) facilitate the achievement of the knowledge integration process. Even if each dimension is empirically identified, none by itself is sufficient to influence the phases of the knowledge integration process. These three dimensions operate jointly as a result of their complementary nature (Nahapiet \& Ghoshal, 1998; Newell et al., 2004). We obtain a different result by considering the internal and external facets of social capital in our empirical study.

Our case study supports the idea that the influence of the internal and external social capital facets differs depending on the phase of knowledge integration considered: collection, interpretation, and assimilation. To achieve collection, external social capital is a major asset that enables formal and informal contacts and rich interactions between the team and other members of the firm. The interpretation phase mainly involves internal social capital to formalize and synthesize the various types of individual and collective knowledge, and then, this leads to the creation of organizational knowledge. Thus, collective work inside the project team, based on frequent meetings and informal interactions, shared values, and shared languages, constitute a lever to adequately realize this common goal. The team spirit helps integrate knowledge through common views on work priorities and is evidenced by quick decision making. For the last phase, assimilation, both internal and external facets of social capital are jointly required. Assimilation refers to the spread and institutionalization of the newly created organizational knowledge throughout the organization, and thus the role of external social capital is clearly revealed as a way to involve as many people as possible. Internal social capital is also crucial, especially to respond to questions asked, to give priority to software evolutions, or to ensure global coherence of the project. The joint influence of the external and internal social capital of the project team is of paramount importance for the completion of the assimilation phase. This analysis of the role of internal/external social capital during knowledge integration offers a refined view of social capital, which previously was viewed as a whole through the multiples phases of integration (e.g. Bhandar et al., 2007). 


\section{Reinforcement of social capital through the achievement of knowledge integration}

In studying the influence of a project team's social capital on knowledge integration, the empirical study highlights the evolution of the social capital during the project, underscoring the existence of a feedback effect. Knowledge integration is a dynamic cycle (Carlile \& Rebentisch, 2003) and a nonlinear process. Carlile and Rebentisch (2003) also emphasize the path-dependent nature of knowledge, which leads us to acknowledge that knowledge integration is dialectic and complex: social capital influences knowledge integration positively, and in turn, social capital is developed through knowledge integration. This effect suggests that the process of knowledge integration affects the social capital of the project team. The modalities of the project, in which knowledge integration takes place, lead to an evolution in the nature and intensity of the relationships of the project team's members. This evolution occurs within the team and outside with other members of the organization: both internal and external facets of social capital evolve. Thus, in the Phenix Project, internal social capital was under construction but grew quickly during the project; complementary external social capital is quite moderate but also evolving. Social capital also is affected through its three dimensions. The structural dimension of social capital is significantly affected by the knowledge integration process. This evolution of the structural dimension helps in the evolution of the cognitive and relational dimensions as well (Tsai \& Ghoshal, 1998). Social interactions lead to more trust in the project team and to an increase in shared values and language. Social capital influences knowledge integration and is shaped through a feedback effect by knowledge integration.

This empirical analysis of the co-evolution of social capital and knowledge integration is a phenomenon rarely studied; most of the literature highlights a one-way direct relationship between social capital and knowledge integration. This co-evolution of social capital and knowledge integration is a long-term effect-the knowledge integration process does not end with the termination of the project. That is, knowledge integration and the project do not follow the same pace. For example, the assimilation phase continues after the end of the project, given that institutionalization of the newly created knowledge is not complete. To summarize, mutual reinforcement occurs between social capital and knowledge integration in the context of a crossfunctional project.

Figure 2 illustrates the differentiated role of social capital in knowledge integration, considering the internal and external facets of social capital. It also takes into account the feedback effect based on the reinforcement of social capital through the achievement of knowledge integration. 


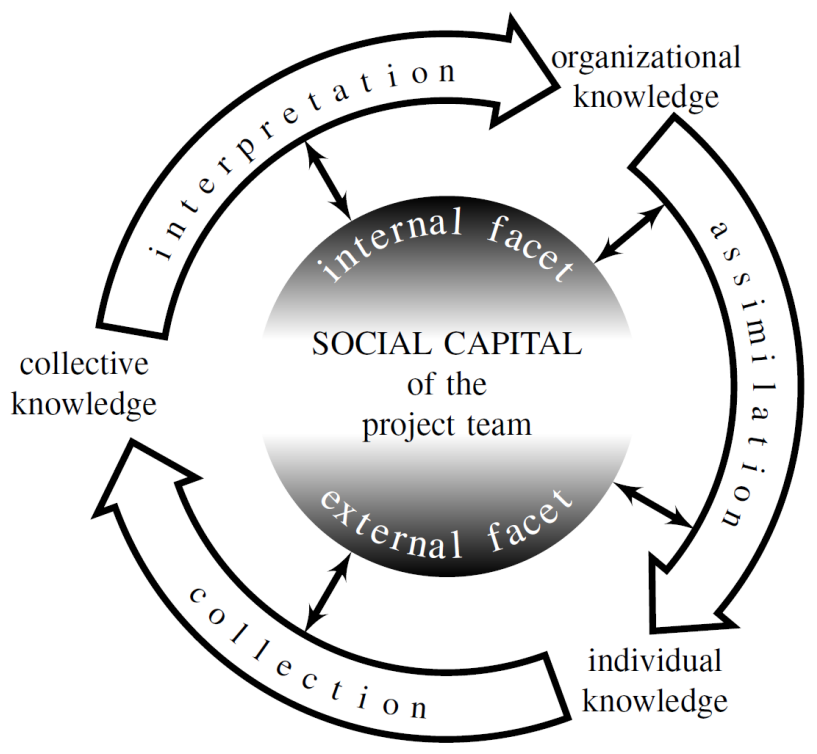

Figure 2. Knowledge integration and social capital in a cross-functional project.

Table 4 summarizes the main findings of our research and analyzes them in the light of existing literature. Our main findings involve several managerial implications regarding project management practices and recommend that social capital be considered during the whole project.

\begin{tabular}{|c|c|c|}
\hline Key findings & Existing literature & Contributions and implications \\
\hline $\begin{array}{l}\text { A 3-phase model } \\
\text { of knowledge } \\
\text { integration }\end{array}$ & $\begin{array}{l}\text { The numerous existing definitions of } \\
\text { knowledge integration insist on the } \\
\text { multiple levels of knowledge involved } \\
\text { and on its processual dimension. The } \\
\text { mechanism of organizational } \\
\text { institutionalization is underlined (Tell, } \\
\text { 2011). }\end{array}$ & $\begin{array}{l}\text { Three intertwined phases of knowledge integration are } \\
\text { identified through the CIA model: Collection (individual } \\
\text { level to collective level), Interpretation (collective level to } \\
\text { organizational level) and Assimilation (organizational level to } \\
\text { individual level). This process is cyclical and operationalized } \\
\text { in a cross-functional project where knowledge is dispersed } \\
\text { through the firm. }\end{array}$ \\
\hline $\begin{array}{l}\text { Existence of } \\
\text { internal and } \\
\text { external facets of } \\
\text { social capital }\end{array}$ & $\begin{array}{l}\text { Previous literature examines social } \\
\text { capital as a whole or refers to the } \\
\text { three dimensions proposed by } \\
\text { Nahapiet \& Ghoshal (1998): } \\
\text { structural, relational and cognitive. }\end{array}$ & $\begin{array}{l}\text { In addition to the three dimensions of Nahapiet and Ghoshal, } \\
\text { our case study underlines the distinction between internal and } \\
\text { external facets of social capital, inside and outside the project } \\
\text { team. } \\
\text { Practically, firms should develop both facets of project team } \\
\text { social capital. Both facets are crucial for the completion of } \\
\text { the whole process of knowledge integration.. }\end{array}$ \\
\hline $\begin{array}{l}\text { Differentiated } \\
\text { role of internal } \\
\text { and external } \\
\text { facets of social } \\
\text { capital during } \\
\text { knowledge } \\
\text { integration }\end{array}$ & $\begin{array}{l}\text { The dynamical influence of social } \\
\text { capital along the project has already } \\
\text { been studied (Bhandar et al., 2007), } \\
\text { but not based on the multiple facets of } \\
\text { the concept. }\end{array}$ & $\begin{array}{l}\text { A balanced role of the social capital is identified, as the two } \\
\text { facets of the social capital have a differentiated influence } \\
\text { during knowledge integration: external facet leads during } \\
\text { collection, while internal facet concerns interpretation and } \\
\text { finally both facets influence assimilation phase. } \\
\text { Practically, a company needs to balance the project team's } \\
\text { social capital: members of the project team will be } \\
\text { successively involved, depending on the characteristics of } \\
\text { their own social capital. }\end{array}$ \\
\hline
\end{tabular}

Co-evolution of Influence of social capital on The reciprocal two-way relationship between knowledge social capital and knowledge integration is the most integration and social capital is evidenced. Social capital 


\begin{tabular}{|l|l|l|}
\hline $\begin{array}{l}\text { knowledge } \\
\text { integration }\end{array}$ & $\begin{array}{l}\text { studied one way direct effect } \\
\text { example Newell et al. 2004) }\end{array}$ & $\begin{array}{l}\text { influences effective achievement of the knowledge } \\
\text { integration process. And in turn, the realization of knowledge } \\
\text { integration is modifying social capital of the project team. } \\
\text { Practically, as project's length is different from knowledge } \\
\text { integration's length, managers should not forget to keep on } \\
\text { managing knowledge integration after completing an IT } \\
\text { project. }\end{array}$ \\
\hline
\end{tabular}

Table 4. Synthesis, putting into perspective and implications of the results

\section{Conclusion}

We acknowledge that knowledge is often mismanaged during project realization. This mismanagement constitutes a lack in understanding of what makes a project successful, especially in the context of large projects involving multiple sources, loci, and owners of knowledge. The objectives of this paper were twofold. First, it aimed to understand the evolution of knowledge during cross-functional projects, and second, it aimed to improve understanding of the role of social capital on the knowledge integration process in such projects. Through the use of a single qualitative investigation, several findings emerge. The case study enabled us to realize that the process of knowledge integration can be interpreted through three intertwined phases: collection, interpretation, and assimilation of knowledge. Social capital constitutes a resource derived from the project team's network of relationships that effectively help it integrate knowledge. This effect is realized through the common influence of the structural, relational, and cognitive dimensions of social capital. Moreover, the joint influence of rapidly created internal social capital in the project team and progressively built external social capital supports the dynamics of knowledge integration. The existence of a project team's social capital enables links to pool knowledge when required for the project. Finally, we conclude that the knowledge integration process influences the social capital of the project team, underscoring the phenomenon of co-evolution.

Our results are supported by a case of an information system project in SME, though we do not claim that our observations on knowledge integration processes can be generalized to other organizational contexts. A cross-functional project is the framework of our conceptual and empirical investigation, and thus further research is required to determine how our findings should be amended to account for different situations, such as projects in large companies or projects made up of virtual teams (Alavi \& Tiwana, 2002). However, our research constitutes an important contribution to the notion of knowledge integration and a useful framework for understanding the role of social capital in knowledge management. 
Finally, we highlight a promising area for further research. Although this study revealed that social capital transforms how knowledge integration occurs during a project, it focused little on the nature of the integrated knowledge. In particular, further research should investigate the question of knowledge specificity and complexity, for example, by considering contextual specificity, technical specificity, and thus complexity. Both knowledge specificity and complexity play a significant role in how knowledge is integrated (Sabherwal \& Becerra-Fernandez, 2005). They therefore could help refine understanding of the influence of social capital, according to the specific nature of the type of knowledge involved. Another important area for further research, which is still at its infancy stage, is the impact of social capital on knowledge integration efficiency in achieving cross-functional projects. This topic could lead to promising and important results for both academics and practitioners. 


\section{References}

Adler P and Kwon SW (2002) Social capital: Prospects for a new concept. Academy of Management Review 27(2), 17-40.

Alavi M and Tiwana A (2002) Knowledge integration in virtual teams: The potential role of KMS. Journal of the American Society for Information Science \& Technology 53(12), 1029-1037.

Becker M (2001) Managing dispersed knowledge: Organizational problems, managerial strategies and their effectiveness. Journal of Management Studies 38(7), 1037-1051.

Bhandar M, Pan SL and Tan B (2007) Towards understanding the roles of social capital in knowledge integration: a case study of a collaborative information systems project. Journal of the American Society for Information Science \& Technology 58(2), 263-274.

Carlile P and Rebentisch E (2003) Into the black box: The knowledge transformation cycle. Management Science 49(9), 1180-1195.

Crossan M, Lane H and White R (1999) An organizational learning framework: From intuition to institution. Academy of Management Review 24(3), 522-537.

Edelman L-F, Bresnen M, Newell S, Scarbrough H and Swan J (2004) The benefits and pitfalls of social capital: Empirical evidence from two organizations in the United Kingdom. British Journal of Management 15(1), 59-69.

El Louadi M (2008) Knowledge heterogeneity and social network analysis - Towards conceptual and measurement clarifications. Knowledge Management Research \& Practice 6(3), 199-213.

Enberg C, Lindkvist L and Tell F (2006) Exploring the dynamics of knowledge integration - Acting and interacting in project teams. Management Learning 37(2), 143-165.

Fong P (2003) Knowledge creation in multidisciplinary project teams: An empirical study of the processes and their dynamic interrelationships. International Journal of Project Management 21(7), 479-486.

Grant R (1996) Prospering in dynamically-competitive environments: Organizational capability as knowledge integration. Organization Science 7(4), 375-387.

Huang J and Newell S (2003) Knowledge integration processes and dynamics within the context of cross-functional projects. International Journal of Project Management 21(3), 167-177.

Inkpen A.C And Crossan M (1995) Believing is seeing: Organizational learning in joint-ventures. Journal of Management Studies 32(5), 595-618.

Inkpen A and Dinur A (1998) Knowledge management processes and international joint ventures. Organization Science 9(4), 454-469.

Kianto A and Jaakowski J (2010) Linking social capital to organizational growth. Knowledge Management Research \& Practice 8(1), 4-14.

Kogut B and Zander U (1992) Knowledge of the firm, combinative capabilities, and the replication of technology. Organization Science 3(3), 383-397.

Leonard-Barton D (1995) Wellsprings of knowledge: Building and sustaining the sources of innovation. Harvard Business School Press, Boston.

Locke A (1999) Some reservations about social capital. Academy of Management Review 24(1), 811. 
Maaninen-Olsson E, Wismen M and Carlsson S (2008) Permanent and temporary work practices: Knowledge integration and the meaning of boundary activities. Knowledge Management Research \& Practice 6(4), 260-273.

Maurer I and Ebers M (2006) Dynamics of social capital and their performance implications: Lessons from biotechnology start-up. Administrative Science Quarterly 51(2), 262-292.

Miles M and Huberman M (1994) Qualitative Data Analysis - An Expanded Sourcebook (2nd ed.). Sage, Newbury Park, CA.

Nah F and Lau LS (2001) Critical factors for successful implementation of enterprise systems. Business Process Management Journal 7(3), 285-296.

Nahapiet J and Ghoshal S (1998) Social capital, intellectual capital, and the organizational advantage. Academy of Management Review 23(2), 242-266.

Newell S, Tansley C and Huang J (2004) Social capital and knowledge integration in an ERP project team: The importance of bridging AND bonding. British Journal of Management 15(1), 43-57.

Nonaka I (1994) A dynamic theory of organizational knowledge creation. Organization Science 5(1), 14-37.

Nonaka I and Takeuchi H, (1995), The Knowledge-creating Company, Oxford University Press, Oxford.

Okhuysen G and Eisenhardt K (2002) Integrating knowledge in groups: How formal interventions enable flexibility. Organization Science 13(4), 370-386.

Organization Studies Special Issue (2004) Project-based organizations, embeddedness and repositories of knowledge. Organization Studies 25(9) 1474-1648.

Payne GT, Moore C, Griffis S and Autry C (2011) Multilevel challenges and opportunities in social capital research. Journal of Management 37(2) 491-520.

Reich BH, Gemino A and Sauer C (2008) Modeling the knowledge perspective of IT projects. Project Management Journal 39(S1), S4-S14.

Sabherwal R and Becerra-Fernandez I (2005) Integrating specific knowledge: Insights from the Kennedy space center. IEEE Transactions on Engineering Management 52(3), 301-315.

Schmickl C and Kieser A (2008) How much do specialists have to learn from each other when they jointly develop radical product innovations? Research Policy 37(3), 473-491.

Sherif H, Hoffman J and Thomas B (2006) Can technology build organizational social capital? The case of a global IT consulting firm. Information \& Management 43(7), 795-804.

Spender JC (2008) Organizational learning and knowledge management: Whence and whither? Management Learning 39(2): 159-176.

Sydow J, Lindkvist L and DeFillippi R (2004) Project-based organizations, embeddedness and repositories of knowledge: Editorial. Organizations Studies 25(9), 1475-1489.

Swan J, Scarbrough H and Newell S (2010) Why don't (or do) organizations learn from projects? Management Learning 41(3): 325-344.

Tell F (2011) Knowledge integration and innovation: A survey of the field. In knowledge integration and innovation: Critical challenges facing international technology-based firms (Bergek A, Hobday M, Berggren C, Bengtsson L and Söderlund J, Eds), pp. 25-69, Oxford University Press, Oxford. 
Tsai W and Ghoshal S (1998) Social capital and value creation: The role of intrafirm networks. Academy of Management Journal 41(4), 464-476.

Wang JK, Ashleigh M and Meyer E (2006) Knowledge sharing and team trustworthiness: It's all about social ties! Knowledge Management Research \& Practice 4(3), 175-186.

Yin R (2003) Case study research: Design and methods (3rd ed). Sage Publication, London. 